\title{
A cidade que não cala: o samba da Pedra do Sal e as formas de comunicação contemporâneas na região portuária do Rio Janeiro
}

THE CITY THAT IS NOT SILENT: THE SAMBA OF PEDRA DO SAL AND THE CONTEMPORARY WAYS OF COMMUNICATION IN THE PORT AREA OF RIO DE JANEIRO

\section{Raquel Paiva}

Professora titular da Escola de Comunicação da Universidade Federal do Rio de Janeiro. Coordenadora do Laboratório de Estudos em Comunicação Comunitária e do Instituto Nacional de Estudos em Comunicação Comunitária. Pesquisadora do Conselho Nacional de Desenvolvimento Científico e Tecnológico.

paivaraquel@hotmail.com

\section{Guilherme Oliveira Curi}

Mestre em Sociologia pela University College Dublin. Doutorando do Programa de PósGraduação em Comunicação da Universidade Federal do Rio de Janeiro. curi.guilherme@gmail.com

Recebido em 26 de fevereiro de 2016. Aprovado em 27 de março de 2016.

\section{Resumo}

O objetivo é compreender a cidade a partir das expressões artísticas que se dão na zona portuária do Rio de Janeiro, local historicamente marcado por encontros interculturais e polifônicos. Para tal, atenta-se para os possíveis diálogos entre a cultura local, que tem como suas mais latentes expressões simbólicas o samba da Pedra do Sal e a intervenção política promovida por gestores públicos municipais. Pergunta-se: o que de fato está em jogo no discurso de revitalização da zona portuária do Rio de Janeiro? Quais aspectos da contemporaneidade podem ser apontados nesse projeto urbanístico e comunicacional?

Palavras-chave: Comunicação. Cultura contemporânea. Música. 


\title{
Abstract
}

Our aim is to understand the city from its artistic expressions that take place in the port area of Rio de Janeiro, which is historically marked by intercultural and polyphonic encounters. Therefore, we pay attention to the possible dialogues between the local culture, which has Pedra do Sal samba as its most symbolic expressions, and the political interventions promoted by the city administrators. We ask: What is really at stake in the revitalization discourse of the port area in Rio de Janeiro? Which aspects of the contemporary society can be pointed out in this communicative and urban project?

Keywords: Communication. Contemporary culture. Music.

\section{Introdução}

\begin{abstract}
A liberdade da cidade é, portanto, muito mais que um direito de acesso àquilo que já existe: é o direito de mudar a cidade mais de acordo com o desejo de nossos corações [...] A liberdade de fazer e refazer a nós mesmos e as nossas cidades dessa maneira é, sustento, um dos mais preciosos de todos os direitos humanos.
\end{abstract} David Harvey et al., Cidades rebeldes: passe livre e as manifestações que tomaram as ruas do Brasil

Não admito viver numa cidade artificial. Todas as cidades que nasceram na maquete do arquiteto e do engenheiro são fascistas. Uma cidade tem que nascer sozinha, em espontâneo

brotar. Não se pode dizer, eu quero uma árvore ali, me tire essa praça daqui [...] Eu leio através das ruínas. A ruína é clara, limpa lente de microscópio [...] Eu quero o erro.

Paulo Leminski, Ensaios e anseios crípticos

Importantes cidades ao redor do mundo, com rica tradição artística, se desenvolveram em função de seus portos marítimos e fluviais, aconteceram a partir deles, floresceram. Veneza, Constantinopla (atual Istambul), Liverpool, Nova Orleans, Hamburgo, Roterdã, Nova Iorque, Londres, Havana, entre tantas outras situadas à beira do mar, nas diferentes costas ribeirinhas e oceânicas do planeta. Durante muitos séculos, o cais portuário foi a primeira fronteira de contato entre civilizações na era moderna. No entorno desses locais circularam e até hoje circulam pessoas de diferentes nacionalidades e culturas.

O Rio de Janeiro, assim como outras cidades portuárias ocidentais, pode ser considerado como um dos primeiros espaços urbanos cosmopolitas da história recente, fato decorrente do transporte fluvial e marítimo ser o primeiro meio de locomoção entre os estados-nações. Para nós, pensar essas cidades sem tratar da importância de seus portos e 
de toda a região em seu entorno é uma tarefa inconcebível. Juntas, elas formam infinitas redes de comunicação, espaços heterogêneos e de socialização, passíveis de diversas interpretações e elucidações.

Dessa forma, traça-se uma linha imaginária que liga os primeiros encontros culturais no cais portuário e o mundo globalizado atual, regido por modelos econômicos especulativos, por tecnologias da comunicação e da informação que nos mantêm conectados, nas chamadas "global cities", ou "cidades globais", expressão cunhada por Saskia Sassien (2013) para denominar determinados pontos nodais de fluxos financeiros, a partir dos quais se obtém controle global dos mercados secundários e locais de produção dispersos, dado que o investimento do capital externo ocorre cada vez mais através de ações e títulos.

E ao fim dessa linha, seguindo a tendência econômica global de outras cidades portuárias, como Barcelona e Buenos Aires, o Rio de Janeiro através de sua prefeitura municipal inicia em 2010 a "revitalização" do porto e da região, a chamada Operação Urbana Porto Maravilha. No mesmo local, encontra-se o samba da Pedra do Sal, reunião tradicional entre sambistas locais, que há mais de um século acontece no Morro da Conceição, conhecido antigamente como "Pequena África", movimento que será descrito a seguir.

\section{Objetivos}

$\mathrm{O}$ artigo em questão tem como objetivo compreender a cidade a partir desses movimentos e do fluxo comunicacional que aconteceu e ainda acontece no cais portuário. Local onde diferentes idiomas e dialetos são falados ao mesmo tempo, onde novidade e passado do mundo moderno ocidental desembarcam, diferentes culturas interagem e, acima de tudo, se comunicam de forma não linear.

Em um primeiro momento, como proposta para discussão, ao observarmos as representações culturais e midiáticas da região portuária do Rio de Janeiro que hoje vivencia o projeto urbano Porto Maravilha nos deparamos com um paradigma. De um lado, a comunidade portuária com sua herança artística e fluxos, que se organiza e se comunica organicamente; de outro, a tentativa do capital, representado por corporações, empresários, poder público e grande mídia, que tentam de todas as formas organizar e formatar o local ao seu modo, para que assim possam implantar diferentes interesses, em uma espécie de mercantilização do que se tem na região.

A realização do projeto Porto Maravilha, com subsídios de empresas multinacionais, e as formas como ele está sendo informado através dos canais de comunicação do próprio projeto e de seus interlocutores, como no site Porto Maravilha, dão indícios suficientes para essa primeira constatação empírica. 
Identificam-se assim, como contraponto a essas tentativas de apropriação do capital e instrumentação das comunidades ali presentes, as conexões e significados produzidos pela e na cidade, na esfera da comunicação oral, dialogal, interpessoal, nas quais a música de rua, como sugerimos, pode ser observada como uma das fortes formas de expressão, resistência e diálogo.

\section{Metodologia}

No cais portuário, as três formas temporais se tornam uma. Chegar, ficar e partir. Estar perto, deslocar-se e distanciar-se. Um tempo único, que só existe ali. Compreendemse assim, em um primeiro momento, as narrativas produzidas por esse tipo de comunicação, consequências da cultura que por hora chamamos de portuária.

Sugerimos assim, empregar o termo "cultura portuária" para denominarmos as redes de significação nas quais essas relações estariam suspensas, assim como sugere Raymond Williams (1979) ao definir cultura como um sistema significante fruto da experiência por meio da qual uma ordem social é comunicada, reproduzida e explorada.

Uma de nossas hipóteses, que procuramos analisar através de uma breve investigação histórica-documental, é a de que essa cultura portuária gera o samba da Pedra do Sal, no bairro da Saúde, localizado no entorno do porto do Rio de Janeiro. Encontro que se deu originalmente fruto da diáspora africana, tema esse que iremos tratar e analisar ao longo desse artigo.

Dessa forma, Burke (2008, p. 107) colabora decisivamente nas reflexões teóricas propostas ao observar o passado "como uma construção dos fatos nos quais as categorias sociais, antes tratadas como se fossem firmes e fixas, agora parecem ser flexíveis e fluídas". Segundo ele, a expressão "encontros culturais" passa a ser utilizada em substituição à palavra etnocêntrica "descoberta", a partir de 1992, com as celebrações dos 500 anos do primeiro desembarque - ou encontro - de Colombo nas Américas, no qual, especialmente historiadores e antropólogos tentam agora descrever não somente a história dos então "descobridores", ou "vencedores" mas também reconstruir as maneiras como os habitantes nativos do Caribe, receberam Colombo.

Assim, propomos traçar um paralelo entre a cultura nativa, oral e musical do samba da Pedra do Sal e a reproduzida pelos interlocutores do projeto, visões essas aparentemente opostas, mas que por vezes se entrecruzam. Pergunta-se: $\mathrm{O}$ que de fato está em jogo nessa chamada revitalização da zona portuária? Quais aspectos da contemporaneidade podem ser apontados nesse projeto urbanístico e também comunicacional?

Para tal, além da revisão histórica proposta já mencionada e da observação crítica das formas discursivas expressas no site do projeto, realizamos entrevistas in loco 
semiabertas com integrantes da comunidade da região portuária, músicos que participam da roda de samba e comerciantes que trabalham durante os encontros semanais que acontecem ali, com o objetivo maior de respondermos tais questionamentos e refletirmos sobre a temática proposta.

Ressaltamos assim que um dos principais argumentos metodológicos e epistemológicos deste artigo é a de que as características culturais, as suas narrativas e as diferentes formas de comunicar de cada uma delas, sublinhadas por suas formas de expressão no contexto portuário, podem ser interpretadas fazendo uso das ciências da comunicação, que cada vez mais atenta para as diferentes formas de convívio social e cultural dentro das grandes metrópoles.

\section{A região portuária do Rio de Janeiro e o samba}

Para uma melhor compreensão dos fatores de como a região portuária do Rio de Janeiro está nos dias atuais, para assim podermos ter uma visão mais precisa das questões sociais, culturais, artísticas e comunicacionais que nos interessam, faz-se necessário realizar um breve recuo historiográfico.

Assim, de acordo com o sociólogo Euler David Siqueira, os portos brasileiros podem ser classificados em ao menos três modelos que mudam ao longo da história, são eles: o porto colonial ou imperial, que surge a partir da abertura dos portos pela coroa portuguesa em 1808; em seguida, passa-se para a fase do porto capitalista moderno ou fordista, que começa na virada do século XIX para o século XX; e, por fim, o porto flexível, que ele denomina hoje de modelo de transição (SIQUEIRA, 2005, p.113).

Ao atentar para o segundo modelo portuário brasileiro, o capitalista moderno ou fordista, que acontece de fato a partir do surgimento do Estado Novo, Siqueira (2005) destaca que ao mesmo tempo em que o porto carioca passava por mudanças, diversas imagens e significados eram atribuídos a esse espaço de socialização.

O ambiente urbano no entorno do porto do Rio de Janeiro passou a ser identificado como um espaço degenerado, sujo, infecto, propício ao desenvolvimento de doenças perigosas que povoavam o imaginário das elites [...]. Os padrões culturais, estéticos e morais das camadas pobres da época foram condenados e, em seu lugar, introduzidos novos valores e comportamentos tidos como modernos [...]. Foi o estado que se colocou como principal agente do processo de ordenar e organizar o espaço social, político e cultural disciplinando as camadas pobres da população que habitavam o entorno portuário. (Ibid., p. 122). 
Em contrapartida, nesse mesmo período, na tentativa de ordenação por parte do Estado, nesses ambientes identificados como espaço degenerado e sujo, encontros culturais aconteciam na boemia da região portuária carioca, nos bares e nos antigos cabarés no entorno das docas, lugares frequentados também por prostitutas, traficantes e marinheiros das mais diversas nacionalidades, onde o improviso aliado com a malandragem se torna essencial para se comunicar e, acima de tudo, para sobreviver. Algo semelhantemente sentido em outras cidades portuárias ao redor do mundo (CURI, 2006).

Nesse sentido, muitos historiadores apontam a região portuária de Storyville, em Nova Orleans, Estados Unidos, como sendo o berço do jazz. Alguns pesquisadores até mesmo afirmam que palavra jazz surge a partir da flor jasmim, perfume predileto das mulheres que frequentavam os clubes de dança em Storyville.

Assim como o jazz, o samba também surgiu na zona portuária, trazido pelos negros com a diáspora africana, e foi, aqui no Brasil, misturado com a cultura ocidental colonial latino-americana. Segundo Muniz Sodré (1998), no livro Samba, o dono do corpo, a partir da segunda metade do século XIX, começaram a aparecer no Rio de Janeiro, os traços da música urbana brasileira. Ele afirma que, apesar de suas características mestiças, uma mistura de influências africanas e europeias, essa música acontecia no âmago da população negra, particularmente depois da abolição da escravatura, quando os negros passam a buscar "novos modos de comunicação adaptáveis a um quadro hostil urbano" (Ibid., p. 13). A própria palavra samba deriva de palavra semba e mesemba, de Angola, que é um tipo de ritual religioso da cultura Yorubá, cultura que também influenciou o jazz (SODRÉ, 1998; CURI, 2006).

Outra válida observação de Sodré é a de que em Nova Orleans, assim como em Salvador (BA) e no Rio de Janeiro (RJ), também eram realizados rituais nagôs na famosa Congo Square, centro de importantes encontros culturais para os negros africanos. Equivalente à Congo Square, de Nova Orleans, teríamos o Cais do Valongo, ou Mercado do Valongo, no Rio de Janeiro, que funcionou entre os anos de 1758 e 1831 na zona portuária carioca, onde hoje também está situada a Comunidade Remanescentes de Quilombos da Pedra do Sal, como veremos a seguir. Nesse sentido, Honorato (2008), ao pesquisar as relações sociais, econômicas e culturais entre os diversos personagens que habitaram a área da cidade, afirma que no local existiram as mais fortes formas de resistência cultural negra da época.

No entanto, o que salientamos aqui é o fato de que essas práticas não existiam somente dentro da comunidade africana de diáspora, de forma hermética e fechada, mas sim através do diálogo com outras culturas, de forma heterogênea e plural, assim como nos lembra Edward Said (2013), ao sugerir que todas as culturas estão envolvidas umas com as outras, nenhuma isolada e pura, mas híbridas, heterogêneas, diferenciadas, não monolíticas e instáveis. 
Eis aí talvez a riqueza maior dessa região, pois, ao analisarmos esses breves relatos históricos, podemos constatar aquilo que Harvey (2013) nos chama a atenção. Para ele, devemos atentar para o direito à cidade e às diferenças que dela emanam. Tal fato seria, segundo o autor, um direito à diferença, um dos mais preciosos direitos dos citadinos. Segundo Harvey (2013, p. 30), a cidade sempre foi percebida como o local dos encontros, "de diferenças e de interação criativa, um lugar onde a desordem tem seus usos e visões, formas culturais e desejos individuais concorrentes se chocam".

Algo semelhante ao pensamento de Berenstein Jacques (2012), que nos impulsiona às próximas reflexões. A autora sugere que aqueles que habitam essa região podem ser considerados como

os habitantes das zonas opacas das cidades, dos espaços do aproximativo e da criatividade' como dizia Milton Santos, das zonas escondidas, ocultadas, apagadas, que se opõem às zonas luminosas, espetaculares, gentrificadas. Uma outra cidade, opaca, intensa e viva insinua assim nas brechas, margens e desvios do espetáculo urbano pacificado. O Outro urbano é o homem ordinário que escapa - resiste e sobrevive - no cotidiano, da anestesia pacificadora. Como bem mostra Michel de Certau, ele inventa seu cotidiano, reinventa modos de fazer, astúcias sutis e criativas, táticas de resistência e de sobrevivência pelas quais se apropria do espaço urbano e assim ocupa o espaço público de forma anônima e dissensual. (Ibid., p. 15).

\section{O samba da Pedra do Sal}

Como brevemente relatamos, na região portuária do Rio de Janeiro está localizada a Pedra do Sal. Nesse local, reuniram-se famosos sambistas como Heitor dos Prazeres (1898-1966), Donga (1890-1974) João da Baiana (1887-1974) e Pixinguinha (1897-1973), este último, tido por muitos como um dos maiores compositores da música brasileira.

Ali, na primeira década do século passado foram compostos os primeiros sambas, inclusive até mesmo aquele que é considerado o primeiro registro fonográfico brasileiro, em 1908, a canção "Pelo Telefone", composta por Donga. Durante anos, a região foi frequentada por diversos artistas. No entanto, como vimos anteriormente, o local sofreu com a precarização das condições sanitárias e de moradia, fazendo que esses encontros vivessem um longo período de ostracismo.

Depois de uma extensa pausa, há cerca de dez anos, duas vezes por semana, artistas, moradores, turistas e estrangeiros que visitam a cidade passaram a se reunir novamente formando uma imensa roda de samba. Como característica dos tempos atuais, um 
site foi criado para divulgar o projeto chamado Roda de Samba da Pedra do Sal ${ }^{1}$, além do encontro também estar inserido nas redes sociais, sugerindo assim novas significações na ordem da representação simbólica e discursiva, tema que poderá ser melhor trabalhado em um novo artigo.

Por ora, atentamos sobre essa retomada dos espaços urbanos no Rio de Janeiro por meio da arte. Nesse sentido, Herschmann e Fernandez (2012) elucidam que, após um longo período de decadência socioeconômica, política e cultural, que teve início com a mudança da capital para Brasília e durou até a segunda metade dos anos de 1990, o Rio de Janeiro, nos últimos anos, vem recuperando o protagonismo no cenário nacional, especialmente no âmbito artístico e cultural. De acordo com os pesquisadores, se, por um lado, os investimentos públicos e privados que são direcionados à cidade por conta da realização de megaeventos esportivos e de entretenimento têm um significativo papel para a reversão desse quadro; por outro, é possível constatar que as atividades musicais também desempenham relevante e estratégica função na chamada revitalização da cidade do Rio de Janeiro.

Tal como pode ser constatado pelo crescente e estrondoso êxito de algumas áreas do centro como a Lapa e a Praça XV - que passaram nos últimos anos a gravitar em torno das atividades musicais. Essas áreas - que antes estavam degradadas e ofereciam riscos à segurança pública - hoje abrigam dois polos históricos, gastronômicos e culturais estratégicos do Rio: o da Lapa (que tem como eixo as ruas Mem de Sá e Lavradio e é um território também conhecido como Polo do Rio Antigo, por contemplar áreas da Cinelândia e da Praça Tiradentes) e o da Praça XV (que tem como eixo central o cruzamento das ruas do Ouvidor e do Mercado). (Ibid., p. 15).

Isso posto, ao frequentarmos o samba da Pedra do Sal, entrevistamos alguns dos músicos responsáveis pela organização do evento, moradores da região e comerciantes que vendem bebidas e alimentos durante os encontros que são frequentados por pessoas de diferentes regiões da cidade, classes sociais e turistas.

De acordo com os artistas do grupo Roda da Pedra, responsável pelo evento, a iniciativa de recuperar (ou até mesmo revitalizar) o samba da Pedra do Sal partiu deles próprios em diálogo com a comunidade do entorno que aos poucos foi sendo receptiva à ideia. Hoje, muitos dos que vivem nas casas próximas aos encontros musicais, que ocorrem todas as segundas e sextas-feiras, comercializam bebidas e alimentos durante a apresentação dos sambas.

A grande maioria dos moradores ressalta que a região melhorou muito depois que as atividades artísticas voltaram a acontecer, exaltando principalmente essa nova forma

1 Mais informações sobre o projeto estão disponíveis em: <http://rodadesambadapedradosal.blogspot.com.br/>. 
de sustento gerada pela visita de turistas e de outras pessoas da cidade que antes não frequentavam o local. É consenso entre os comerciantes entrevistados que a comunidade local está sendo beneficiada pelos encontros musicais.

Um fator importante constatado, após a breve pesquisa de campo realizada, é que somente depois de alguns anos do samba voltar a acontecer é que o poder público, através do projeto Porto Maravilha, passou a perceber e apoiar a ideia dos músicos. As consequências práticas dessa percepção, a partir dos gestores municipais, foram a instalação de banheiros públicos e o envio de dois policiais para fazer a chamada ronda no local.

No entanto, a partir das entrevistas, foi constatado também que há certo receio por parte dos protagonistas do encontro em firmar algum tipo de acordo com o poder público municipal, devido, principalmente, a divergências políticas e ao fato de que o projeto, assim informado pelos músicos e comerciantes, "anda com suas próprias pernas". Vale ressaltar também que para a realização dos eventos não é necessário grandes estruturas, pois durante o samba da Pedra do Sal há pouca amplificação dos instrumentos, os músicos levam seus próprios equipamentos ao ar livre e por vezes contam com uma pequena tenda, sentam-se como se em uma mesa de bar e ali se forma uma grande roda ao lado da conhecida pedra.

Dessa forma, ao observarmos esses processos de comunicação de sociabilidade através da música, constatamos com atenção uma hipótese também sugerida por Herschmann $(2012$, p. 2), de que "a espacialidade quando articulada com a música e o entretenimento tem potencialmente grande capacidade de mobilização no mundo contemporâneo". Ainda segundo o autor:

é possível afirmar que a música ao vivo experienciada presencialmente (as interações geradas nos concertos, rodas, jam sessions e eventos espetacularizados promovem condições para a realização de estesias e afetos) e quando articulada com certos perfis arquitetônicos e geográficos dos lugares (tais como as ruas-galerias, praças e parques temáticos) construiriam condições favoráveis para o entretenimento e para a ressignificação das territorialidades e do cotidiano urbano. (Ibid., p. 4).

Podemos observar também algo sustentado por Sodré (1998 2011), ao afirmar que comunicação seria sinônimo de experiência, de participar de algo, pôr-se em comum. Segundo ele, a ideia de transmissão de informação não tem nada a ver com o conceito original da palavra. Comunicação se torna, assim, a principal forma organizativa deste novo mundo em que vivemos, o fazer organizativo daquilo que é fundamental para o humano, que seria o comum. Em outras palavras, a comunicação estaria até no silêncio, 
principalmente no não dito, na reunião, na música, algo que podemos observar nos encontros gerados na Pedra do Sal.

Em contrapartida, foi observado que no site oficial do projeto Porto Maravilha, que existe paralelamente aos encontros musicais que acontecem ali, em maior escala, existem diversas ações que procuram incluir a história e a arte principalmente africana e também de outras culturas. Assim, como reflexão inicial questiona-se: Essas ações não seriam reapropriações de algo que já acontece pela própria comunidade, uma sistematização econômica, que buscaria em última instância transformar a área portuária em um imenso shopping center, uma área mercadologicamente atrativa e regulada? Revitalizar seria então uma tentativa mercadológica de sistematizar o cais portuário?

Assim, ao observarmos o contexto atual da zona portuária do Rio de Janeiro, sugerimos que os interesses políticos, ao tentarem governar os interesses culturais da comunidade daquela região, podem ser observados como uma tentativa de estipular uma versão particular de sociedade, mas que de nenhum modo pode ser considerada única.

A cultura (portuária) que se dá pode também assim ser considerada como uma crítica ao capitalismo e às posições que se opõem a ele, resultante de um conflito político. Como bem nos lembra Raymond Williams (1979, p. 53): "o complexo de sentidos indica um argumento complexo acerca das relações entre desenvolvimento humano geral e um modo de vida particular, e entre ambos e as obras e práticas da arte e da inteligência".

Nesse sentido, Stuart Hall (2000, p. 72) propõe ao observar os processos culturais como "práticas vividas ou ideologias práticas que capacitam uma sociedade, grupo ou classe a experimentar, definir, interpretar e dar sentido às suas condições de existências". Algo semelhante ao pensamento de Eagleton (2011, p. 117) ao referenciar a cultura como "uma espécie de pedagogia ética que nos torna aptos para a cidadania política ao liberar o eu ideal ou coletivo escondido dentro de cada um de nós".

\section{Cidade-espetáculo?}

Seguindo essa linha de raciocínio, ressalta-se aqui também o interesse midiático em forma de megaeventos na zona portuária como uma tentativa de tornar a região turisticamente mais atrativa e exaltar a cidade para o mundo, características latentes e clássicas da sociedade do espetáculo de Debord (1997, p. 14), ao perceber que esse processo não seria "um conjunto de imagens, mas uma relação social entre pessoas mediadas por imagens $[\ldots]$ uma visão de mundo que se objetivou".

Assim, de acordo com Herschmann (2005, p. 2), ao se formular uma análise mais aprofundada da dinâmica da sociedade contemporânea se torna quase impossível não 
levar em conta o fenômeno do espetáculo. Para o autor, no entanto, o espetáculo contemporâneo parece indicar "a emergência de uma nova arena política - midiática - e a importância da esfera da cultura ou dos fatores culturais como vetores capazes de mobilizar efetivamente os atores sociais hoje".

Ainda segundo Herschmann, outra hipótese que permeia este argumento é o fato de que a espetacularização e a alta visibilidade, construídas no ambiente midiático, seriam estratégicas para que discursos e ações políticas alcancem êxito.

Já para Freitas (2011, p. 3), os megaeventos são tidos como mídia por exporem justamente os "cosmopolitismos, as culturas nacionais e as culturas locais, propondo traduções interculturais a cada dado". Um dos primeiros megaeventos no Rio de Janeiro, por exemplo, que foi a Exposição Nacional de 1908, mesmo sendo realizado na Praia Vermelha, atual bairro da Urca, comemorava o centenário da abertura dos Portos no Brasil e o desembarque da família real.

Na contemporaneidade, vale ressaltar que esta atenção midiática teve início há alguns anos anteriores ao projeto Porto Maravilha. Alguns eventos podem ser citados, como: a chegada do navio francês Cargò no final da década de 1980, levando milhares de pessoas ao píer Mauá; a Primavera dos Livros, em 2002, encontro literário realizado nos armazéns do porto carioca; no mesmo ano, o Mercado Mundo Mix, feira voltada a comercializar novas tendências da moda e da arte; as esculturas do artista plástico Amilcar de Castro em 2004, entre outras atividades comerciais e artísticas que culminam no chamado projeto de "revitalização", que hoje, a partir de uma hipótese empírica que se deseja ser verificada, parece gerar uma série de conflitos de interesse nos níveis econômico, social, político e cultural.

Segundo Vainer (2013, p. 37), a cidade dos megaeventos "precipita, intensifica, generaliza a cidade de exceção e a democracia direita do capital". Para o pesquisador, as cidades são concebidas como empresas em concorrência umas com as outras pela atração de capitais. Dessa forma, elas são oferecidas no mercado global pelo poder público, entregando capitais cada vez mais móveis. Com isso, segundo ele, "a guerra fiscal torna-se apenas uma das formas da 'urbanidade global', que empurra coalizões locais de poder a buscarem articulações em níveis nacional e internacional que assegurem a cada cidade uma inserção, mesmo que subordinada, no mercado" (Ibid., p. 38).

Assim, justifica-se também atentar para a mídia impressa hegemônica carioca, visando a compreender como estão sendo reproduzidas determinadas ações do projeto Porto Maravilha, levando em consideração a ressalva de Sodré (2011) ao conceber a informação produzida pelas grandes corporações midiáticas como biombo ideológico da financeirização. De acordo com o autor, torna-se necessário vislumbrar o fato de que o 
midiático, enquanto categoria particular da forma-espetáculo, pode existir fora dos suportes tecnológicos, na medida em que coincida com o mundo em si apartado da ação política imediata do ser social e organizado pela "abstração mágica do espetáculo ou da profecia. Ou seja, a comunicatividade em si mesma torna-se espetacular e fascinante" (Ibid., p. 69). Nesse sentido, a palavra "maravilha" se torna exemplo latente e elucidativo dessa forma-espetáculo que Sodré traz à luz. Algo que atrai, seduz e produz no imaginário coletivo a suficiente empatia para a realização de intervenções do poder estatal.

Avançando na discussão, para Caiafa (2007, p. 22), tais ações estão na corrente de "um imenso processo de privatização das cidades, ou de desurbanização, resultando em uma topografia urbana fortemente segmentada". Dessa forma, a autora analisa que:

a cidade orientada para o carro de fato parece mais adequada ao modo de dominação que predomina no capitalismo contemporâneo e que Deleuze chama de "controle". Diferentes disciplinas, em que se precisa fechar num espaço para vigiar - no modelo da escola, do hospital, da fábrica, da prisão -, essa outra forma de dominação envolve um controle ‘ao ar livre'. (Ibid,, p. 23).

Isso resulta no que Caiafa (2007, p. 24) chama de "anticidade privatizada", uma forma que, segundo ela, "impõe-se quando faltam as condições para a resistência a essa forma de dominação que caracteriza as mais recentes mutações do capitalismo". E sua primeira vítima seria a aniquilação da alteridade, que negaria a experiência fortemente urbana do contágio, da mistura e da interação.

\section{Polifonias que não calam}

Ao analisar os eventos musicais produzidos pela comunidade ali presente na Pedra do Sal, percebe-se o que Maffesolli (1998, p. 170) observa como a multiplicidade de grupos fortemente unidos por sentimentos comuns algo que para ele permite estruturar uma memória coletiva que, na sua própria diversidade é fundadora. Esses grupos podem ser de diversas ordens (étnicas, sociais), mas estruturalmente, seria a sua "diversidade que assegura a unicidade da cidade. Sua vida no dia-a-dia assegura a ligação entre o tempo e o espaço. Ele é o guardião não-consciente da socialidade" (loc. cit.).

Assim, um dos conceitos clássicos que ajudam a reforçar as formas como a cultura se dá naquela região seria o de "polifonia", "heteroglossia" ou "poliglossia" de Mikhail Bakhtin. Estamos cientes de que o sociolinguista russo utiliza o termo para descrever gêneros de fala e suas diferentes vozes que podem ser ouvidas em um texto. No entanto, além do campo literário, esse conceito pode ser aplicado ao cais portuário e suas formas de 
resistência onde diferentes vozes de diferentes dialetos e diferentes culturas são ouvidas e interpretadas ao mesmo tempo, onde não há centro e se vive uma relatividade generalizada. Entre outras palavras, a organicidade da comunicação enquanto forma de expressão.

Dessa forma, para captar essa aparente polifonia cultural, nos lembra Maffesoli (1998, p. 201) de que não mais se trata, portanto, de um corte ou até mesmo de uma "ruptura epistemológica", de distanciamento crítico - mas, antes, de uma compreensão do presente popular através de variações intelectuais que não demonstram, mas que dizem.

Polifonias urbanas que podem também ser interpretadas como experiências errantes, nas quais, segundo Jacques (2012, p. 11) "a principal potência em questão está na construção e na (contra)produção de subjetividades, de sonhos e de desejos". Ainda de acordo com a pesquisadora:

as narrativas urbanas resultantes dessas experiências realizadas pelos errantes, sua forma de transmissão e compartilhamento, podem operar como potente desestabilizador de algumas partilhas hegemônicas do sensível e, sobretudo, das atuais configurações anestesiadas dos desejos. (loc. cit.).

Acredita-se assim que a análise dessas expressões comunicacionais, que acontecem a partir dos encontros musicais, nas quais a ocupação dos espaços públicos e urbanos pela população se dá de forma ativa e latente, proporcionam questões fundamentais para que tenhamos um olhar mais atento sobre a contemporaneidade e as ressignificações produzidas no tempo presente. Ao atentarmos para os diálogos proporcionados por esses processos poderemos talvez encontrar caminhos mais errantes e menos sistematizados em nossas cidades.

\section{Referências}

BAKHTIN, M. Estética da criação verbal. 4. ed. São Paulo: Martins Fontes, 2003.

BURKE, P. O que é história cultural? 2. ed. Rio de Janeiro: Zahar, 2008.

CAIAFA, J. Aventura das cidades: ensaios e etnografias. 1. ed. Rio de Janeiro: FGV, 2007.

CAIAFA, J.; ELHAJJI, M. (Orgs.). Comunicação e sociabilidade: cenários contemporâneos. Rio de Janeiro: Mauad X, 2007

CURI, G. The music from the sea: social and cultural aspects on the creation of jazz and samba. 2006. Dissertação (Mestrado em Sociologia) - University College Dublin, Dublin, 2006.

DEBORD, G. A sociedade do espetáculo. Rio de Janeiro: Contraponto, 1997.

EAGLETON, T. A ideia de cultura. 2. ed. São Paulo: Ed. Unesp, 2011. 
FREITAS, R. Rio de Janeiro, lugar de eventos: das exposições do início do século XX aos megaeventos contemporâneos. In: COMPÓS, 20., 2011, Porto Alegre: Compós, 2011.

HALL, S.; WOODWARD, K.; SILVA, T. (Org.). Identidade e diferença: a perspectiva dos estudos culturais. Petrópolis: Vozes, 2000.

HARVEY, D. et. al. Cidades rebeldes: passe livre e as manifestações que tomaram as ruas do Brasil. São Paulo: Boitempo, 2013.

HERSCHMANN, M. (Org.). Espetacularização e alta visibilidade: a politização da cultura hip-hop no Brasil contemporâneo. In: HERSCHMANN, M.; FREIRE FILHO, J. (Orgs.). Comunicação, cultura e consumo: a (des)construção do espetáculo contemporâneo. Rio de Janeiro: E-papers, 2005. p. $153-168$.

HERSCHMANN, M., FERNANDES, C. S. Potencial movente do entretenimento, da música e espacialidade no Rio de Janeiro In: ENTRETENIMENTO, FELICIDADE E MEMÓRIA - FORÇAS MOVENTES DO CONTEMPORÂNEO, 1., São Paulo. São Paulo: Anadarco, 2012, p. 13-34.

HERSCHMANN, M.; FREIRE FILHO, J. (Orgs.). Comunicação, cultura e consumo: a (des)construção do espetáculo contemporâneo. Rio de Janeiro: E-Papers, 2005.

HONORATO, C. Valongo: o mercado de escravos do Rio de Janeiro, 1758 a 1831. Niterói: UFF, 2008.

JACQUES, P. Elogio aos errantes. Salvador: Edufba, 2012.

LEMINSKI, P. Ensaios e anseios crípticos. Campinas: Unicamp, 2011.

MAFFESOLI, M. O tempo das tribos: o declínio do individualismo nas sociedades de massa. São Paulo: Forense Universitária, 1998.

SASSEN, S. The global city: New York, London, Tokyo. Princeton: Princeton University Press.

SAID, E. O orientalismo: o oriente como invenção do ocidente. São Paulo: Companhia de Bolso, 2013.

SIQUEIRA, E. Cidades e portos: metamorfoses em espaços sociais complexos. In: FREITAS, R.; NACIF, R. (Orgs.). Destinos da cidade: comunicação, arte e cultura. Rio de Janeiro: Eduerj, 2005. p. 111-141.

SODRÉ, M. Samba, o dono do corpo. 2. ed. Rio de Janeiro: Mauad X, 1998. . As estratégias sensiveis. Afeto, Mídia e Política. Petrópolis: Vozes, 2006. . Antropológica do espelho: uma teoria da comunicação linear e em rede. 6. ed. Petrópolis: Vozes, 2011.

VAINER, C. Quando a cidade vai às ruas. In: HARVEY, D. et. al. Cidades rebeldes: passe livre e as manifestações que tomaram as ruas do Brasil. São Paulo: Boitempo, 2013.

WILLIAMS, R. Do reflexo à mediação. In: . Marxismo e literatura. Rio de Janeiro: Zahar, 1979. 